\title{
Methicillin Resistant Staphylococcus Aureus in a Liver Abscess
}

\author{
Lt Col JM Sloss \\ FRCS(Ed), MRCPath, RAMC \\ Consultant Pathology \\ Maj JRC Bowen \\ MRCP, RAMC \\ Neurological Registrar
}

Departments of Pathology and Medicine, British Military Hospital, Rinteln, BFPO 31

SUMMARY: The case is described of a 30-year-old man who presented to the Army Medical Services with
pyogenic liver abscess from which methicillin resistant Staphylococcus aureus (MRSA) was isolated.

MRSA in pyogenic liver abscess has to date not been reported in the recent English literature.

\section{Introduction}

MRSA is a cause of infection in many countries (1). Treatment is difficult and costly (2). Isolation from a liver abscess has not to date been reported in the English literature.

We report a case of MRSA in a 30-year-old British soldier with a hepatic abscess managed by percutaneous drainage.

\section{Case Report}

A 30-year-old soldier sustained a ruptured liver in Croatia in January 1993 as result of a fall whilst fitness training. The injury was repaired locally and the patient was transferred back to Queen Elizabeth Military Hospital, Woolwich. On admission he was found to have bilateral pleural effusions and a hepatic artery aneurysm, which was subsequently embolised at Kings College Hospital, London. MRSA was isolated from the laparotomy wound and stool. The phage type was 622/626.

He returned to Germany, where he was based, in April 1993 but required admission to the British Military Hospital Rinteln in September 1993 complaining of right shoulder tip pain, night sweats and fever. Examination revealed a right basal consolidation and an intermittent pyrexia. Investigations demonstrated a marked neutrophilia, a grossly elevated C Reactive Protein, and a raised Gamma G T. Transaminases. Albumin, and bilirubin were normal. Chest radiography showed consolidation of the right base. An ultrasound scan and CT of the liver revealed an abscess measuring $5 \times 8 \mathrm{~cm}$ in the right lobe. $500 \mathrm{mls}$ of pus was initially drained from he abscess through a subcostal drain which was then left in situ.
MRSA was isolated from this pus which was of a identical phage type to that isolated at Woolwich. The organism was resistant to erythromycin, tetracyclw gentamicin, fusidic acid, and ciprofloxacin, but sensitive to clindamycin, rifampicin, teicoplanin $\frac{1}{2} \mathrm{~d}$ vancomycin.

Initial antibiotic therapy was vancomycin 1 Gram intravenously, but this was stopped after 10 days.

The drain remains in situ 18 months later. The volime of drainage was initially a litre of fluid daily but this gradually decreased to an intermittent drainage of a fez mls weekly. The abscess cavity continues to be managed conservatively with an in dwelling catheter.

\section{Discussion}

Pyogenic liver abscesses are caused by a wide range of organisms of which $S$ aureus is one of the most commopi The mortality rate varies from $2.2 \%$ to $53 \%$ depending of the aetiology (3). The currently preferred managemen option is percutaneous drainage if possible but if not the surgery (4).

Despite good initial drainage it has taken a long time eradicate MRSA in this patient. This was partly related ti the extensive previous surgery including embolisation his hepatic artery and also the difficulty in treating his MRSA. There is however no evidence that this organis was a particularly virulent strain.

MRSA is an ever present threat to military personn deployed to a wide range of locations, especially whem local medical assistance is required. Infection contro policies are in place within the United Kingdom Defence Medical Services to identify this problem and to preveng importation of infection into receiving military hospitafs in the United Kingdom and in Germany. 


\begin{abstract}
JM Sloss and JRC Bowen
The MRSA isolated from this patient was not a recognised epidemic strain and the organism did not spread beyond the abscess cavity, nevertheless the difficulty in eradicating the organism was well illustrated in this case.
\end{abstract}

\section{Acknowledgement}

We would like to thank Col J H Johnston Late RAMC for permission to report this case and Dr R R Marples of the Staphylococcus Reference Laboratory PHLS Central Public Health Laboratory for carrying out the phage typing. $\stackrel{c}{3}$

REFERENCES

1. Maple PAC, Hamilton-Miller JMT, Brumfitt W. World-wide antibiotic resistance in methicillinresistant Staphylococcus aureus. Lancet 1989; 1 (8637): 537-40.

2. Working Party Report. Revised guidelines for the control of epidemic methicillin-resistant Staphylococcus aureus. J. Hosp Infect 1990; 19: 351-377.

3. Macdonald MI. Pyogenic liver abcess: Diagnosis, Bacteriology and treatment. Eur J Clin Microbiol 1984; 3: No. 6 506-509.

4. McCorkel. SJ, Niles NL. Pyogenic liver abscesses: Another look at medical management. Lancet. 1985; 1 (8432): 803-6. 